\title{
INVENTÁRIO ARBÓREO EM DOIS BAIRROS PAULISTANOS, JARDIM DA SAÚDE E VILA VERA, LOCALIZADOS NA SUBPREFEITURA DE IPIRANGA ${ }^{1}$
}

\author{
Adriana Ines Napias Rossetti ${ }^{2}$, Armando Reis Tavares ${ }^{3}$ e Paulo Renato Mesquita Pellegrino ${ }^{4}$
}

RESUMO - Foi realizado levantamento quantiqualitativo de vegetais de porte arbóreo em dois bairros paulistanos, Vila Vera e Jardim da Saúde, situados na região Sudeste de São Paulo, não distando muito entre si, porém com características de ocupação de uso do solo bastante distintas. No Jardim da Saúde, encontraram-se 1.033 exemplares de 72 espécies botânicas, cuja altura média de todas as árvores foi de 8,07 m. A Caesalpinea peltophoroides Benth. foi a espécie mais frequente, com 20,68\%, seguida da Largestroemia indica L., com 7,48\%. Predominavam árvores com mais de 8,50 m de altura, sendo o pior indicador de sanidade vegetal a infestação de cupins, com 8,33\% do total. Apenas 23,33\% tinham situações de permeabilidade do passeio suficiente, e 5,71\% delas se encontravam com conduções de podas para desobstrução das redes aéreas; o rebaixamento das árvores aconteceu em 7,74\% dos exemplares. Na Vila Vera havia 178 árvores pertencentes a 42 espécies botânicas, sendo a média da altura total de 6,31 m. A espécie mais abundante foi a Caesalpinea peltophoroides Benth., com 24,71\%; a segunda seria a Ligustrum lucidum W.T. Aiton, com 17,24\% do total. Em 42,70\% das árvores, a altura foi inferior a 4,50 m, e a sanidade vegetal estava comprometida em $12,37 \%$ dos exemplares pela infestação de cupins. Somente $7,87 \%$ dos exemplares estavam em situações de permeabilidade suficiente, as conduções de poda para desobstrução de redes eram de 3,38\% e as podas de rebaixamento, de 13,48\%. Havia uma média de 16,85 m de afastamento entre árvores no Jardim da Saúde, enquanto na Vila Vera esse indicativo era de 38,68 m.

Palavras-chave: Arborização urbana, Inventário de árvores e Cidade de São Paulo.

\section{ARBOREAL INVENTORY OF TWO SÃO PAULO CITY NEIGHBOORHOODS (JARDIM DA SAUDE AND VILA VERA) LOCATED IN IPIRANGA DISTRICT ZONE}

\begin{abstract}
An arboreal qualitative and quantitative study was conducted in two closely located neighborhoods (Vila Vera and Jardim da Saúde) in the southeast region of São Paulo. In spite of geographical vicinity, both neighborhoods have very different land occupation characteristics. In Jardim da Saúde we found 1033 tree specimens, belonging to 72 distinct botanic species, with an average height of $8.07 \mathrm{~m}$. Caesalpinea peltophoroides Benth. was the most frequent species found (20,68\% of the trees), followed by Largestroemia indica L. (with 7.48\%) Most trees have a height of $8.50 \mathrm{~m}$ and above. The worst health threat was termite infestation which affected $8.33 \%$ of the specimens. Only $23.33 \%$ of the trees were planted in an area which enough surface permeability. $5.71 \%$ of the specimens had been pruned to prevent interference with electrical lines and crownreducing pruning had been done in $7.74 \%$ of the trees. In Vila Vera we found limited space conditions in regards to the width of the sidewalk and also in regards to the predominant type of site utilization. We counted 178 trees belonging to 42 distinct botanic species, with average height of $6.31 \mathrm{~m}$. The most common species is Caesalpinea peltophoroides Benth. (which accounted for $24.71 \%$ of the specimens), followed by a Ligustrum lucidum W.T. Aiton (with 17.24\%). In this neighborhood $42.70 \%$ of the trees had a height of less than $4.5 \mathrm{~m}$, $12.37 \%$ were in poor health due to termite infestation. Only $7.87 \%$ of the specimens where planted in an area which enough surface permeability, while $16.85 \%$ where located in totally paved areas. $3.38 \%$ had been pruned to avoid interference with electrical lines and $13.48 \%$ had been crown-reducing pruned. In Jardim da Saúde the average distance between trees was $16.85 \mathrm{~m}$, while in Vila Vera it was 38.68m. In other words, the average distance between trees is about 2.29 greater in Vila Vera than in Jardim da Saúde.
\end{abstract}

Keywords: Urban trees, Arboreal inventory e São Paulo city.

\footnotetext{
${ }^{1}$ Recebido em 05.10.2008 e aceito para publicação em 02.03.2010.

${ }^{3}$ Instituto de Botânica, IBT, Brasil. E-mail: <rossetti@hotmail.com>.

${ }^{4}$ Universidade de São Paulo, USP, Brasil. E-mail: <atavares2005@yahoo.com.br>.
} 


\section{INTRODUÇÃO}

O estudo da vegetação de porte arbóreo nas áreas urbanas constitui tema de averiguação bastante complexo relativamente novo no campo de conhecimento científico e que envolve a interdisciplinaridade de diversas áreas. Numa abrangência maior, poder-se-ia dizer que a própria ecologia do meio urbano e seus ecossistemas específicos mostram-se pouco conhecidos. Nos processos de ocupação urbanos, ditados pelo imediatismo da exploração econômica, o binômio destruição e construção é privilegiado sob quaisquer instâncias, num processo de desconstruções espaciais alienados, desnecessários e abusivos, com a substituição frequente de ecossistemas importantes por áreas que constituirão futuramente espaços-problemas nos contextos das cidades (MOTA, 2003).

Muitas vezes, os bairros são caracterizados pelo seu contexto histórico, os seus limites variam de acordo com a cartografia utilizada. Nesse levantamento foram utilizados os dados de regularização de loteamentos e arruamentos existentes no Setor de Cadastro da Subprefeitura de Ipiranga. O bairro denominado Vila Vera, localizado no Distrito de Sacomã, sofreu regularização posterior à sua implantação, ficando denominado arruamento regularizado; o Jardim da Saúde, localizado no Distrito de Cursino, teve a planta do loteamento previamente regularizada pelo incorporador e ficou cadastrado como loteamento aprovado. A área total do arruamento Vila Vera totalizava $198.594 \mathrm{~m}^{2}$. No loteamento do Jardim da Saúde, totalizaram-se $700.000 \mathrm{~m}^{2}$ na segunda gleba.

O Bairro Vila Vera tem padrão de ocupação bastante característico de urbanização de pequenos lotes com casas sem recuos laterais para permitir o melhor aproveitamento do lote. O recuo frontal, quando existente, visa ao abrigo de veículos no interior do imóvel. Os passeios são de largura insuficiente para abrigar comodamente o tráfego de pedestres. Os transeuntes acabam invadindo o leito das vias públicas para seus trajetos, em conflito de ocupação das vias com o trânsito local de veículos. As Avenidas Nossa Senhora das Mercês e Vergueiro funcionam como corredores de ligação viária possuindo tráfego intenso de veículos em todas as horas do dia. Não se encontram facilmente referências históricas de ocupação do sítio.

O Jardim da Saúde tem tamanho maior nos lotes originais propostos e traçados das vias públicas aproveitando as curvas de níveis do terreno. O público a que se direcionava esse loteamento, na época do lançamento, possuía menores recursos financeiros do que aquele que adquiriu lote de glebas planejadas pela Cia City, em áreas como Pacaembu e Jardim América, que havia ocorrido há três décadas.

Em 1943, o Decreto Municipal n 206 dispõe sobre a oficialização e denominação das ruas do Bairro Jardim da Saúde. Em 1945, os moradores formam a Sociedade de Amigos Jardim da Saúde, visando à solução de questões relativas ao melhoramento urbano: calçamento, condução e falta de luz nas ruas entre as mais urgentes. A arborização desse bairro em 1970 já existia como elemento urbano significativo (JORGE, 1970).

Os objetivos deste trabalho seriam entre outros: testar metodologias de inventários de arborização urbana de acompanhamento viário totais no Município de São Paulo; conhecimento do patrimônio arbóreo em duas localidades que, apesar da proximidade geográfica, apresentaram modelos de ocupação do solo urbano bastante distinto, tentando perceber como se dão essas diferenciações e seus reflexos no tema objeto de estudo, e, por último, poder-se-ía citar a contribuição para início de embasamento de futuras discussões técnicas sobre Plano_Diretor de Arborização Urbana num território com a complexidade e abrangência de uma metrópole, com suas diferentes condicionantes e contextos, no qual o poder público local instituído mostra muito tímidas incursões no desenvolvimento de planejamento ambiental que tenha possibilidades técnicas integradas e ações que se perpetuem no tempo na área da arborização urbana.

\section{MATERIAIS E MÉTODOS}

\subsection{Dados físicos e sociais}

O Clima Tropical Úmido de Altitude do Planalto Paulista foi considerado para os dois bairros, com mesoclima de altas colinas e cumeadas planas do espigão central e colinas, patamares e rampas da face leste do espigão central (SÃO PAULO, 2004).

Barro e Bacelli (1979) citaram que o rio Tamanduateí e sua calha impõem o modelo de relevo da região na paisagem do Ipiranga. A calha parece ter esculpido formas de relevo abatidas que não chegam a $5 \%$ de declividade. A cada afluente das margens encaixam-se colinas alongadas, entre as cotas, de 725 m (nível médio dos rios e córregos) e 800 m de elevação máxima. Pela ordem, o córrego do Ipiranga, afluente do Tamanduateí, define na sua margem esquerda, a Oeste, a colina onde está a Avenida Lins de Vasconcelos (Subprefeitura 
da Sé) e, na sua margem direita, a Leste, a colina onde se localiza a Avenida Nazaré, com o Parque da Independência (centro velho do Ipiranga).

Existem cinco bacias hidrográficas que se situam na área da atual Subprefeitura de Ipiranga: Moinho Velho, Ipiranga e Meninos, este último divide os Municípios de São Paulo, São Bernardo do Campo e São Caetano. As três bacias principais são afluentes, da montante a jusante, dos rio Tamanduateí, ribeirão dos Meninos, córrego do Moinho Velho e riacho do Ipiranga,.

O distrito do Cursino apresentava, segundo os Censos do IBGE, população de 110.435 habitantes em 1991, tendo havido decréscimo de população no ano de 2000, quando se verificou que o total era de 102.089 habitantes. Houve, portanto, variação de população que tende ao estacional com índice de variação negativa de 0,9244 no período. Por sua vez, o distrito do Sacomã teve população de 211.200 habitantes em 1991 e 228.283 habitantes em 2000. O crescimento da população teve incremento de 1,080\% no período. Em relação ao perfil socioeconômico, a população do distrito do Cursino ocupa a $34^{\mathrm{a}}$ posição entre os 96 distritos do município. As melhores classificações com esse indicador, para o Município de São Paulo, ficam com os distritos de Jardim Paulista, Moema e Santo Amaro. No perfil socioeconômico, a população do distrito do Sacomã tem a $57^{\mathrm{a}}$ posição. As piores classificações pertencem aos Distritos de Marsilac, Cidade de Tiradentes e Lajeado (SÃO PAULO, 2004).

A cobertura vegetal no Distrito de Cursino em 1999 somava $4.463 .100 \mathrm{~m}^{2}$, definindo um índice de cobertura vegetal por habitante de $44,34 \mathrm{~m}^{2} \mathrm{hab}^{-1}$. Esse indicativo é inferior ao encontrado na região metropolitana para o mesmo indicativo, que foi de 73,66 $\mathrm{m}^{2} \mathrm{hab}^{-1}$ Em 1999, no Distrito de Sacomã a cobertura vegetal era de $1.188 .000 \mathrm{~m}^{2}$, com índice de cobertura vegetal de 5,24 $\mathrm{m}^{2} \mathrm{hab}^{-1}$. Esse indicativo é, em muito, inferior ao encontrado na região metropolitana e também muito abaixo do encontrado no Distrito de Cursino (SÃO PAULO, 2004). O índice de cobertura vegetal do Distrito de Cursino considerou o Parque das Fontes do Ipiranga, sob a responsabilidade do Estado de São Paulo, no qual se localizam o Jardim Botânico e o Zoológico.

O desmatamento total do Distrito de Cursino foi calculado com base nas imagens de satélite Landsat 5 em 23 de outubro de 1991, em comparação com imagens do Landsat 7 em 30 de abril de 2000 e apresentaram um total de 0,18 ha de vegetação suprimida no período. $\mathrm{O}$ desmatamento do Distrito de Sacomã no período 1991-2000 foi de 22,59 ha, área essa expressivamente maior da apresentada para o Distrito de Cursino. Nota-se que os indicadores de qualidade ambiental no Distrito de Sacomã estão abaixo dos encontrados no Distrito de Cursino (SÃOPAULO, 2004). Isso poderia ser explicado por Sacomã ser um distrito com urbanização menos consolidada, possuindo incorporações imobiliárias de prédios de apartamentos residenciais naquele período, e essa tendência de verticalização ainda se nota bastante presente.

\subsection{Metodologias do inventário arbóreo}

Este inventário classifica-se como total ou censo da população arbórea nos dois bairros selecionados e foi realizado no mês de agosto de 2006. Foram inventariados todos os indivíduos (árvores e palmeiras) com diâmetro à altura do peito, estimado visualmente superior a 0,03 m. Excluíram-se todas as árvores que estavam em áreas verdes adjacentes às ruas inventariadas. As medições do tronco foram feitas pela obtenção da circunferência à altura do peito.

Os dados levantados em campo se coletaram da seguinte forma: 1. Quanto à localização do exemplar arbóreo; nome do logradouro público, numeração correspondente, caráter de uso de via, largura média do leito carroçável, afastamento predial, largura da calçada, medida da guia até o tronco da árvore; 2. Quanto à presença de instalações de equipamentos urbanos; 3. Quanto à situação do sistema radicular e suas interferências; 4. Quanto ao exemplar arbóreo; nome da espécie botânica, medida de circunferência à altura do peito, medida com fita métrica, altura total, em metros utilizando prancha dendrométrica (hipsômetro simples), altura da primeira bifurcação medida com trena se até 4,50 m de altura e prancha dendrométrica em alturas maiores a essa altura; 5. Quanto ao desenvolvimento biológico; inclinação do tronco, qualidade do tronco, situação de desenvolvimento da copa e anotações de árvores mortas; e 6. Quanto ao manejo; modalidades de podas encontradas e anotações de plantios.

Os dados referentes ao inventário total dos dois bairros foram cadastrados em planilhas de Microsoft Excel e posteriormente transferidos para programa MicrosoftAccess.

\section{RESULTADOS E DISCUSSÃO}

\subsection{Jardim da Saúde}

O total de exemplares arbóreos levantados foi de 1.033 indivíduos. Na variável principal, número de árvores por quilômetro existia distribuição variando de 216,67

Revista Árvore, Viçosa-MG, v.34, n.5, p.889-898, 2010 
árvores $\mathrm{km}^{-1}$, com afastamento médio de 4,62 m, na Rua Nova Pátria, ao apresentado na Rua Dom Macário, que possui 15,28 árvores $\mathrm{km}^{-1}$ e 65,45 m de afastamento médio. Existe, portanto, gradiente bastante irregular de distribuição de indivíduos. Notou-se número significativo de vegetais arbóreos no Jardim da Saúde (Tabela 1).

Tabela 1 - Ruas do Jardim da Saúde e Vila Vera com variável número de árvores por km e afastamento médio.

Table 1 - Streets in Jardim da Saúde and Vila Vera with variable number of trees per km and average distancing.

\begin{tabular}{|c|c|c|c|c|}
\hline \multicolumn{5}{|l|}{ Jardim da Saúde } \\
\hline Logradouro & Árvores & Extensão total (m) & Árvores por km & $\begin{array}{r}\text { Afastamento } \\
\text { médio (m) }\end{array}$ \\
\hline Abraão de Moraes & 58 & 445 & 130,34 & 7,67 \\
\hline Artur Dias & 46 & 912 & 50,44 & 19,83 \\
\hline Bento de Faria & 7 & 250 & 28 & 35,71 \\
\hline Carlos M. Paolera & 42 & 1070 & 39,25 & 25,48 \\
\hline Carlos Tiago Pereira & 92 & 1488 & 61,83 & 16,17 \\
\hline Cursino & 41 & 1140 & 35,96 & 27,8 \\
\hline Divinópolis & 27 & 840 & 32,14 & 31,11 \\
\hline Dom Macário & 11 & 720 & 15,28 & 65,45 \\
\hline Fonseca Da Costa & 62 & 800 & 77,5 & 12,9 \\
\hline Fco. G. Giordano & 10 & 240 & 41,67 & 24 \\
\hline Frei Rolim & 176 & 2130 & 82,63 & 12,1 \\
\hline João de Santa Maria & 44 & 1150 & 38,26 & 26,14 \\
\hline Loreto & 27 & 396 & 68,18 & 14,67 \\
\hline Lustosa Da Cunha & 7 & 120 & 58,33 & 17,14 \\
\hline Marcos Fernandes & 17 & 930 & 18,28 & 54,71 \\
\hline Nova Pátria & 52 & 240 & 216,67 & 4,62 \\
\hline Oscar Bressane & 71 & 1372 & 51,75 & 19,32 \\
\hline Ribeiro Lacerda & 129 & 1916 & 67,33 & 14,85 \\
\hline Vitor Costa & 114 & 1244 & 91,64 & 10,91 \\
\hline Total & 1.033 & 17.403 & 59,36 & 16,85 \\
\hline \multicolumn{5}{|l|}{ Vila Vera } \\
\hline Logradouro & Árvores & Extensão total (m) & Árvores por km & $\begin{array}{r}\text { Afastamento } \\
\text { médio (m) }\end{array}$ \\
\hline Abagiba & 1 & 290 & 3,45 & 290,00 \\
\hline Alcides Boscolo & 1 & 190 & 5,26 & 190,00 \\
\hline Angelica Kauffman & 2 & 290 & 6,90 & 145,00 \\
\hline Antonio de Jesus Manuel & 2 & 350 & 5,71 & 175,00 \\
\hline Armando Matar & 8 & 340 & 23,53 & 42,50 \\
\hline Atílio Pioli & 15 & 440 & 34,09 & 29,33 \\
\hline Carlos Augusto Carteiro & 7 & 250 & 28,00 & 35,71 \\
\hline Conselheiro Pereira Carvalho & 11 & 220 & 50,00 & 20,00 \\
\hline Jamil Hajaj & 15 & 320 & 46,88 & 21,33 \\
\hline Marco Bertuolo & 15 & 340 & 44,12 & 22,67 \\
\hline Monsenhor du Dreneuf & 26 & 820 & 31,71 & 31,54 \\
\hline Nossa Senhora das Mercês & 14 & 760 & 18,42 & 54,29 \\
\hline Padre José Monteiro & 7 & 150 & 46,67 & 21,43 \\
\hline Ribeirão Bonito & 36 & 650 & 55,38 & 18,06 \\
\hline Romão Piuggari & 8 & 680 & 11,76 & 85,00 \\
\hline Teresa Paulo & 2 & 373 & 5,36 & 186,50 \\
\hline Vergueiro & 10 & 500 & 20,00 & 50,00 \\
\hline Total & 180 & 6963 & 25,85 & 38,68 \\
\hline \multicolumn{5}{|l|}{ Jardim da Saúde } \\
\hline Logradouro & Árvores & Extensão total (m) & Árvores por km & $\begin{array}{r}\text { Afastamento } \\
\text { médio (m) }\end{array}$ \\
\hline Vergueiro & 10 & 500 & 20,00 & 50,00 \\
\hline Total & 180 & 6963 & 25,85 & 38,68 \\
\hline
\end{tabular}

Revista Árvore, Viçosa-MG, v.34, n.5, p.889-898, 2010 
Encontraram-se 80,45\% dos exemplares defrontes a imóveis que possuíam no mínimo recuo de 2,50 m das construções dentro do imóvel ou que não tinham construções no lote. Isso indica que, pelo menos, árvores de médio porte poderiam ser plantadas nos locais onde não existisse arborização no passeio público, ou se necessitasse fazer replantio, não se considerando as limitações impostas por outros equipamentos urbanos ou largura dos passeios. A distribuição da consulta para altura total das árvores mostra que existe predominância em unidades com mais de 8,50 m de altura, e no outro extremo verificou-se que $27,78 \%$ das árvores estão na classe de altura máxima até 4,50 m (Tabela 2).

O maior problema que compromete a sanidade vegetal é a infestação de cupins com 8,33\% do total das árvores. Ressalta-se, no entanto, que a metodologia de análise foi visual, não sendo feita prospecção do tronco. Então, ao avaliar casos em que fenotipicamente as árvores se mostrassem saudáveis, mas que porventura apresentassem infestação interna dos insetos, pode ter havido resultados subestimados da presença de cupins. Devido à biologia de ação da praga urbana, esse ataque no interior do tronco, sem sintomas externos que o comprovem, tem descrição de ocorrência na literatura consultada. O número de exemplares com ataque de cupins é inferior ao número de árvores com oco aparente, e isso se dá porque somente foram analisados os casos nos quais existe algum indicativo real da presença desses insetos. Muitas vezes, apesar de haver ocos aparentes, que seriam da ordem de 9,29\% no Jardim da Saúde, os troncos não se encontravam com sinais de ataque de cupins que mostre visivelmente sua presença (Tabela 2).

A maior quantidade de árvores está localizada em passeios que variam sua largura entre 1,00 e 2,00 m, com 72,80\% do total de distribuição de largura de passeio. As redes de distribuição de energia elétrica são o maior entrave ao pleno desenvolvimento das árvores, e 22,07\% estavam em conflito com a rede primária e 22,75\% com a rede secundária (Tabela 2 ).

A profusão de galhos epicórnicos foi o item mais representativo na avaliação do item de qualidade da copa, existindo em 10,07\% das árvores. Demonstra-se que as podas não têm respeitado os mecanismos de defesa natural dos vegetais contra super brotações. A execução de procedimentos de podas não está preservando as estruturas de colo e crista na base de inserção dos galhos. Outra situação seria as mudas de arbustos e arvoretas, com condução para copa única, que não tiveram desbrota de ramificações laterais na condução pós-plantio. Isso comprometeria o objetivo principal de plantio de árvores de menor porte. Em referência ao inventariado, 13,65\% teve anotações de má qualidade de copa (Tabela 2). Em relação ao total amostrado, 20,62\% apresentou algum indicativo de má qualidade de tronco, como mostrado nessa mesma tabela.

Apenas 23,33\% do total de árvores se encontravam com situações de permeabilidade do passeio suficiente. Áreas acima de 2,00 $\mathrm{m}^{2}$ para árvores de pequeno porte e 3,00 $\mathrm{m}^{2}$ em árvores de médio e grande portes foram consideradas apropriadas no desenvolvimento minimamente sustentável de tais vegetais. As situações de permeabilidade insuficiente somam 76,67\% das árvores plantadas em vias públicas (Tabela 2).

A Caesalpinia peltophoroides Benth. foi a espécie mais frequente, seguida do Lagerstroemia indica L. e do Ligustrum lucidum W.T. Aiton, e essas três espécies somam 35,05\% do total de indivíduos desse bairro. A única espécie que apresenta valores de distribuição quantitativa superiores aos indicados na literatura, como o máximo de exemplares de uma espécie recomendado em determinada população, seria a Caesalpinia peltophoroides, com mais de $10 \%-15 \%$ de presença no Jardim da Saúde (GREY e DENEKE, 1978).

Rocha et al. (2004), em levantamento da arborização de vias públicas em Nova Iguaçu, Rio de Janeiro, encontraram grande número de espécies, 46 no Bairro Rancho Novo e 59 no Centro. Esses autores atribuiram essa diversidade aos plantios contínuos e aleatórios, realizados pela própria população local. Quanto à distribuição das espécies menos frequentes, tem-se que ocorreram 19 com apenas um indivíduo, correspondendo a 3\% do total no Bairro Rancho Novo. Por sua vez, no Centro encontraram 15 espécies com apenas um indivíduo, correspondendo a 1,1\% da população arbórea desse bairro.

Encontram-se 5,71\% da população no Jardim da Saúde, com condução de poda em "L" ou "V”. Outro ponto que cabe destaque seria o rebaixamento total em $7,74 \%$ dos exemplares, manejo de poda conceituado como extremamente contraindicado na condução de árvores urbanas. Em 23,25\% das árvores havia sinais de realização de podas da parte aérea.

Revista Árvore, Viçosa-MG, v.34, n.5, p.889-898, 2010 
Havia 72 espécies de árvores nesse bairro. A diversidade de espécies botânicas no Jardim da Saúde é superior ao encontrado no Bairro de Vila Vera, que somou a presença de 41 espécies botânicas. Deve-se analisar, contudo, que o número de árvores na Vila Vera representa $17,23 \%$ do total existente no Jardim da Saúde, concluindo-se que a diversidade de espécies botânicas arbóreas, perante a população total, apresenta-se

Tabela 2 - Afastamento predial, altura total das árvores, frequência de distribuição em cada classe de altura, fitossanidade, relação das árvores com largura da calçada, situação da qualidade da copa, situação da qualidade do tronco e relação das árvores com o passeio nos Bairros Jardim da Saúde e Vila Vera, São Paulo, SP.

Table 2 - Distance between buildings, total trees height and frequency of distribution for each height segment, trees health, trees distribution in relationship to sidewalk width conditions, conditions of the trees crowns and conditions of the trunks on neighborhoods Jardim da Saúde and Vila Vera, São Paulo, SP.

\begin{tabular}{|c|c|c|c|c|}
\hline \multirow[b]{2}{*}{ Afastamento predial } & \multicolumn{2}{|c|}{ Jardim da Saúde } & \multicolumn{2}{|l|}{ Vila Vera } \\
\hline & Árvores & Freqüência & Árvores & Freqüência \\
\hline Até 2,5 metros & 202 & 19,55 & 08 & 4,49 \\
\hline De 2,5 a 4 metros & 203 & 19,65 & 45 & 25,28 \\
\hline Maior de 4 metros & 562 & 54,40 & 70 & 39,33 \\
\hline Sem afastamento & 44 & 4,26 & 43 & 24,16 \\
\hline Sem construção & 22 & 2,13 & 12 & 6,74 \\
\hline \multicolumn{5}{|l|}{ Altura total } \\
\hline Até $4,5 \mathrm{~m}$ & 287 & 27,78 & 76 & 42,70 \\
\hline De 4,5 a $6,5 \mathrm{~m}$ & 220 & 21,30 & 27 & 15,17 \\
\hline De 6,5 a $8,5 \mathrm{~m}$ & 152 & 14,71 & 29 & 16,29 \\
\hline Mais de $8,5 \mathrm{~m}$ & 374 & 36,21 & 46 & 25,84 \\
\hline \multicolumn{5}{|l|}{ Fitossanidade } \\
\hline Cupins & 86 & 8,33 & 22 & 12,36 \\
\hline Problemas inespecíficos & 74 & 7,16 & 19 & 10,67 \\
\hline Parasitas & 15 & 1,45 & 4 & 2,25 \\
\hline \multicolumn{5}{|l|}{ Largura da calçada } \\
\hline Até 1 m & 124 & 12,00 & 16 & 8,99 \\
\hline de 1 a $2 \mathrm{~m}$ & 752 & 72,80 & 99 & 55,62 \\
\hline de 2 a $3 \mathrm{~m}$ & 69 & 6,68 & 51 & 28,65 \\
\hline Maior de $3 \mathrm{~m}$ & 88 & 8,54 & 12 & 6,74 \\
\hline \multicolumn{5}{|l|}{ Qualidade da copa } \\
\hline Profusão de galhos & 104 & 10,07 & 61 & 34,27 \\
\hline Clorose & 3 & 0,29 & 5 & 2,81 \\
\hline Estressada & 32 & 3,10 & 21 & 11,80 \\
\hline Prejudicada por vandalismo & 2 & 0,19 & 2 & 1,12 \\
\hline \multicolumn{5}{|l|}{ Qualidade do tronco } \\
\hline Injuriado & 76 & 7,36 & 10 & 5,90 \\
\hline Oco aparente & 96 & 9,29 & 19 & 10,92 \\
\hline Fendido & 25 & 2,42 & 11 & 6,32 \\
\hline Anelado & 16 & 1,55 & 4 & 2,30 \\
\hline \multicolumn{5}{|l|}{ Relação com passeio } \\
\hline Pavimentado até o tronco & 128 & 12,39 & 14 & 7,87 \\
\hline Permeabilidade suficiente & 241 & 23,33 & 30 & 16,85 \\
\hline Permeabilidade insuficiente & 664 & 64,28 & 134 & 75,28 \\
\hline \multicolumn{5}{|l|}{ Tipo de poda } \\
\hline Poda em L & 19 & 1,84 & 3 & 1,69 \\
\hline Poda em V & 40 & 3,87 & 3 & 1,69 \\
\hline Irregular & 60 & 5,83 & 4 & 2,25 \\
\hline Topiária & 33 & 3,19 & 6 & 3,37 \\
\hline Levantamento de copa & 8 & 0,78 & 14 & 7,87 \\
\hline Rebaixamento de copa & 80 & 7,74 & 24 & 13,48 \\
\hline
\end{tabular}

Revista Árvore, Viçosa-MG, v.34, n.5, p.889-898, 2010 
relativamente menor no Jardim da Saúde em relação ao existente na Vila Vera. Silva Filho e Bortoleto (2005), em análise da arborização viária de Águas de São Pedro, notaram que os bairros com maior quantidade de árvores também possuem maior diversidade, e isso mostraria que, em Águas de São Pedro, provavelmente a arborização não foi planejada pelo poder público local em aproximação ao que aconteceu em Vila Vera, bairro onde as árvores foram, em sua maioria, plantadas pela população residente.

Em estudo da arborização urbana em uma área da cidade de Lajeado, RS, Ruschel e Leite (2002) verificaram que as 69 espécies levantadas indicam elevada riqueza específica, considerando-se tratar de área urbana, com manejo antrópico e que os plantios irregulares (45 espécies) com pequeno número de indivíduos seriam o principal fator da diversidade. Este também é o caso dos dois bairros analisados aqui.

A altura média de todas as árvores do bairro é de 8,07 $\mathrm{m}$ e a altura da primeira bifurcação, 1,97 m. Em levantamento de arborização na Estância de Águas de São Pedro, Bortoleto (2004) observou, nos indivíduos cadastrados, a altura média de 5,10 m, o diâmetro médio do caule à altura do peito de $0,38 \mathrm{~m}$.

Rocha et al. (2004), em levantamento da arborização de vias públicas em Nova Iguaçu, Rio de Janeiro, afirmaram que aproximadamente $55 \%$ das plantas do Bairro Centro tiveram anotações de altura inferior a 6,00 m, acima de $6,00 \mathrm{~m}$ e inferior a $11,00 \mathrm{~m}$ de altura se encontravam $35,8 \%$ das árvores e com altura superior a 11,00 m estavam 9\% naquele bairro. No Bairro Rancho Novo, a discrepância entre as duas classes de altura extremas era maior, com $37,3 \%$ dos indivíduos com altura de 1,00 a 3,50 m e apenas $3,3 \%$ com altura superior a $11,00 \mathrm{~m}$.

Malvasi et al. (1994), que fizeram inventário do Município de Itaguaí, Rio de Janeiro, anotaram que foi observado que a altura média total estava em 6,81 m. Conclui-se que existe arborização mais antiga, ou com árvores de maior porte, em Itaguaí, no Bairro Centro, em Nova Iguaçu, e no Bairro do Jardim da Saúde, comparando-se com o Município de Águas de São Pedro, o Bairro de Vila Vera, como se pode ver a seguir, e o Bairro Rancho Novo, em Nova Iguaçu.

\subsection{Vila Vera}

Foram inventariadas 178 árvores no Bairro da Vila Vera de 41 espécies botânicas. A altura total média das árvores no Bairro da Vila Vera era de 6,31 m e a altura da primeira bifurcação, de 1,81 m. Havia frequência de distribuição variando de 55,38 árvores $\mathrm{km}^{-1}$, com afastamento médio de 18,06 m na Rua Ribeirão Bonito, e a distribuição apresentada na Rua Abagiba, possuía 3,45 árvores $\mathrm{km}^{-1}$ e 290 m de afastamento médio entre elas. Os números da variável número de árvores $\mathrm{km}^{-1}$ são inferiores aos apresentados no Jardim da Saúde (Tabela 1).

O afastamento médio possuía 16,85 m no Jardim da Saúde, sendo na Vila Vera ese número da ordem de $38,68 \mathrm{~m}$, portanto o afastamento médio da Vila Vera seria 2,29, na média do bairro, maior do que o do Jardim da Saúde.

Há em 71,35\% das situações encontradas afastamento predial superior a 2,50 m ou imóveis livres de construção. Os números entre os dois bairros no quesito afastamento predial são bastante semelhantes, indicando, também aqui, possibilidade de arborização com árvores de porte de médio para grande em todas essas situações (Tabela 2).

Existe número significativo de árvores com altura inferior a $4,50 \mathrm{~m}$, somando $42,70 \%$ do total do inventariado. Esse indicativo apresenta-se inversamente contrário ao encontrado no Jardim da Saúde. A segunda classe de árvores mais representativa desse item de classes de altura total é o de árvores com mais de 8,50 m, totalizando $25,84 \%$ da população da Vila Vera (Tabela 2).

A espécie mais frequente de pequeno porte nos dois bairros foi a Largerstroemia indica L., que apareceu com presença de $7,48 \%$ em relação ao amostrado no Jardim da Saúde e 8,62\% na Vila Vera (Tabela 3).

A espécie de grande porte mais abundante na Vila Vera foi a Caesalpinia peltophoroides, com $24,71 \%$ de presença diante do total amostrado. A segunda foi o Ligustrum lucidum, com 17,24\% do total de vegetação arbórea na Vila Vera. No Jardim da Saúde, essas duas espécies também estavam nos dois primeiros lugares, e a Caesalpinia peltophoroides tinha 20,62\% de presença e o Ligustrum lucidum, $6,87 \%$. Outra espécie que apareceria entre as mais frequentes nos parâmetros de médio e grande portes seria a quaresmeira, que respondia pela terceira colocação no Jardim da Saúde $(5,42 \%)$ e em quarto na Vila Vera, com 4,60\% (Tabela 3).

Revista Árvore, Viçosa-MG, v.34, n.5, p.889-898, 2010 
A maioria das árvores estava localizada em passeios, que variavam sua largura entre 1,00 e 2,00 m, com 55,62\% do total. O segundo padrão de distribuição de largura de passeios seria os que se encontravam entre 2,00 e 3,00 m, apresentando condições favoráveis ao desenvolvimento de vegetais de porte arbóreo, na primeira situação, ao menos, com espécies de médio porte, sem serem considerados outros impedimentos (Tabela 2).

O maior impedimento ao crescimento das árvores nesse bairro se dava pela interferência com a rede secundária de distribuição, somando 23,03\% nesse item, seguido da presença de garagens com 17,42\%; em terceiro, a existência de fiações de redes primárias. Os fatores de entradas de água domiciliar, redes subterrâneas de gás, ramais de luz e presença de postes correspondem a $11,24 \%, 8,05 \%, 7,87 \%$ e $6,18 \% \%$, respectivamente.
Do total, a população da Vila Vera $(50,00 \%)$ apresentavam maus indicadores de qualidade de copa. Os indivíduos com indicadores de má qualidade de copa são quase quatro vezes o número dos encontrados no Jardim da Saúde (Tabela 2).

Em pertinência ao total amostrado, 25,44\% apresentou algum indicativo de má qualidade de tronco. O número é bastante semelhante ao encontrado no Jardim da Saúde para esse mesmo indicativo de qualidade da biologia vegetal, que totalizou naquela situação 22,82\% do total de árvores com alguma injúria ao tronco (Tabela 2). Na Vila Vera, a situação do ataque de cupins $(12,37 \%)$ foi ligeiramente maior ao número de árvores com ocos aparentes, 10,92\% (Tabela 2).

Tabela 3 - Espécies mais frequentes no Jardim da Saúde Vila Vera, São Paulo, SP.

Table 3 - Most common species found at Jardim da Saúde and Vila Vera, SP.

\begin{tabular}{|c|c|c|c|}
\hline \multicolumn{4}{|l|}{ Jardim da Saúde } \\
\hline Nome científico & Nome comum & Freqüência & Numero árvores \\
\hline Chorisia speciosa A. St.-Hil. & Paineira & 2,14 & 22 \\
\hline Tabebuia heptaphylla (Vell.) Toledo & Ipê roxo & 2,33 & 24 \\
\hline Syagrus romanzoffiana (Cham.) Glassman & Jerivá & 2,82 & 29 \\
\hline Dypsis lutescens (H. Wendl.) Beentje \& J. Dransf. & Areca bambu & 2,91 & 30 \\
\hline Livistona chinensis (Jacq.) R. Br. ex Mart. & Latania & 3,01 & 31 \\
\hline Tabebuia avellanedae Lorentz ex Griseb. & Ipê rosa & 3,01 & 31 \\
\hline Bauhinia variegata $\mathrm{L}$. & Bauhinia & 3,30 & 34 \\
\hline Ficus microcarpa L. f. & Ficus microcarpa & 3,59 & 37 \\
\hline Ficus benjamina L. & Ficus benjamina & 4,17 & 43 \\
\hline Tabebuia chrysotricha (Mart. ex A. DC.) Standl. & Ipê amarelo & 4,47 & 46 \\
\hline Tipuana tipu (Benth.) Kuntze & Tipuana & 5,05 & 52 \\
\hline Tibouchina granulosa (Desr.) Cogn & Quaresmeira & 5,44 & 56 \\
\hline Ligustrum lucidum W.T. Aiton & Legustro & 6,89 & 71 \\
\hline Lagerstroemia indica L. & Resedá & 7,48 & 77 \\
\hline Caesalpinia peltophoroides Benth. & Sibipiruna & 20,68 & 213 \\
\hline Outras & & 23,01 & 237 \\
\hline \multicolumn{4}{|l|}{ Vila Vera } \\
\hline Duranta repens $\mathrm{L}$. & Duranta & 1,72 & 3 \\
\hline Stenolobium stans (L.) Seem. & Ipê de Jardim & 1,72 & 3 \\
\hline Dypsis lutescens (H. Wendl.) Beentje \& J. Dransf. & Areca Bambu & 2,30 & 4 \\
\hline Ficus benjamina L. & Ficus Benjamina & 2,30 & 4 \\
\hline Tabebuia heptaphylla (Vell.) Toledo & Ipê Roxo & 2,30 & 4 \\
\hline Tabebuia avellanedae Lorentz ex Griseb. & Ipê Rosa & 2,87 & 5 \\
\hline Tabebuia chrysotricha (Mart. ex A. DC.) Standl. & Ipê Amarelo & 3,45 & 6 \\
\hline Hibiscus rosa-sinensis L. & Hibisco & 4,02 & 7 \\
\hline Tibouchina granulosa (Desr.) Cogn & Quaresmeira & 4,02 & 7 \\
\hline Bauhinia variegata $\mathrm{L}$. & Bauhinia & 4,60 & 8 \\
\hline Murraya paniculata (L.) Jack & Falsa Murta & 4,60 & 8 \\
\hline Lagerstroemia indica $\mathrm{L}$. & Resedá & 8,62 & 15 \\
\hline Ligustrum lucidum W.T. Aiton & Legustro & 17,24 & 30 \\
\hline Caesalpinia peltophoroides Benth. & Sibipiruna & 24,71 & 43 \\
\hline Outras & & 17,82 & 31 \\
\hline
\end{tabular}

Revista Árvore, Viçosa-MG, v.34, n.5, p.889-898, 2010 
Apenas 7,87\% do total de árvores estavam localizadas em situações de permeabilidade do passeio suficiente. $O$ indicador de permeabilidade suficiente do passeio apresentou-se inferior ao apresentado no Jardim da Saúde, que naquela situação apresentou 23,33\% do total, com situação favorável de permeabilidade. O número de exemplares pavimentados até o tronco mostrou mais mal resultado também na Vila Vera, onde $16,85 \%$ se encontravam nessa situação, em comparação com 12,39\% daquele outro bairro (Tabela 2).

A Caesalpinia peltophoroides foi a espécie mais frequente, seguida do Ligustrum lucidum e Lagerstroemia indica, e essas três espécies acabavam somando 50,57\% do total dos indivíduos desse bairro. Quanto ao total amostrado, 22 espécies botânicas apresentavam apenas um exemplar arbóreo (Tabela 3).

As conduções de poda em "L" e "V" são da ordem de 3,38\%. Conclui-se, portanto, que o número de exemplares com manejo de poda para contemplar a coexistência com redes de distribuição é baixo diante do total da população amostrada. O número com poda de rebaixamento de copa soma $13,48 \%$ do total, sendo também maior do que no outro bairro, com 7,74\% dos exemplares arbóreos (Tabela 3).

\section{CONCLUSÕES}

Nos dois bairros havia a necessidade de direcionamento nas ações de tratos de manejo agroflorestais, sendo verificado que não existiam calendários de execução de podas da parte aérea, e as espécies eram podadas, independentemente das características individuais de seus ciclos biológicos anuais.

Os plantios de mudas são tímidos e não garantem a reposição, e que dirá incremento, da população arbórea nos dois bairros. Parece ter havido planejamento da arborização na época da implantação do Jardim da Saúde, porém isso não teve permanência temporal, e acabaram ocorrendo plantios feitos pela população que não tiveram sucesso na escolha de árvores mais adequadas para passeios.

Os índices qualitativos apresentaram todos o pior resultado no Bairro da Vila Vera, em comparação com o Jardim da Saúde.

Os passeios no Bairro de Vila Vera tinham largura menor do que no Jardim da Saúde, sendo nesse primeiro a largura média dos lotes também menor, com menos espaço disponível defronte das residências. Assim, o desafio de incrementar a arborização de bairros com essas características pressupõe trabalhos de requalificação do projeto e largura dos canteiros das árvores e constitui problema semelhante ao que se notou em diversos bairros periféricos em relação ao dito centro expandido da cidade de São Paulo.

\section{REFERÊNCIAS}

ANDRADE, T. O. de Inventário e análise da arborização viária da estância turística de Campos do Jordão, SP. 2002. 112f. Dissertação (Mestrado) - Escola Superior de Agricultura “Luiz de Queiroz”, Universidade de São Paulo, Piracicaba, 2002.

BARRO, M.; BACELLI, R. Ipiranga, bairros de São Paulo. Série: história dos bairros de São Paulo, v. 14. Ipiranga. São Paulo: Prefeitura do Município de São Paulo, Secretaria de Cultura, Departamento do Patrimônio Histórico, 132 p. 1979.

\section{BORTOLETO, S. Inventário} qualiquantitativo da arborização viária da Estância de Águas de São Pedro-SP. 2004. 85f. Dissertação (Mestrado em Agronomia) - Escola Superior de Agricultura "Luiz de Queiroz”, Piracicaba, 2004.

CAVALHEIRO, F.; DEL PICCHIA, P. C. D. Áreas verdes: conceitos, objetivos e diretrizes para o planejamento. In: ENCONTRO NACIONAL SOBRE ARBORIZAÇÃO URBANA, 4, Vitória. Anais... v. 1. Vitória, 1992. p.29-38.

GREY, G. W.; DENEKE, F. J. Urban Forestry. New York: John Wiley, 1978. 279p.

JORGE, A. F. O Bairro do Jardim da Saúde. História dos bairros de São Paulo, Departamento de Cultura da Secretaria de Educação e Cultura da Prefeitura do Município de São Paulo, v.5, 1970.

MALAVASI, U.C.; AGUIAR SOBRINHO, J.; GAMA, L.L.M.F.; ANDRADE, A.G.; ROCHA, A.R. Inventário e recomendações para a arborização urbana na sede do Município de Itaguaí, RJ, CONGRESSO BRASILEIRO DE ARBORIZAÇÃO URBANA, ENCONTRO NACIONAL SOBRE ARBORIZAÇÃO URBANA, 5, Anais... São Luiz, 1994. P.533-537.

Revista Árvore, Viçosa-MG, v.34, n.5, p.889-898, 2010 
MEneghetTi, G. I. P. Estudo de dois métodos de amostragem para inventário da arborização de ruas dos bairros da orla marítima do Município de Santos, SP. 2003. 100p. Dissertação (Mestrado em Recursos Florestais, opção: Silvicultura e Manejo Florestal) Escola Superior de Agricultura "Luiz de Queiroz”, Universidade de São Paulo, Piracicaba, 2003.

MOTA, L. C. Planejamento urbano e conservação ambiental. Estudo de caso: Goiânia-GO. 2003. 216 f.

Dissertação (Mestrado em Ecologia e Recursos Naturais) - Universidade Federal de São Carlos, São Carlos, 2003.

ROCHA, R. T.; LELES, P. S. S.; OLIVEIRA neto, S. N. Arborização de vias públicas em Nova Iguaçu, RJ: o caso dos bairros rancho novo e centro. Revista Árvore, v.28, n.4, p.599-607, 2004.
RUSCHEL, D.; LEITE, S. L. de C. Arborização urbana em uma área da cidade de Lajeado, Rio Grande do Sul, Brasil. Caderno de Pesquisa Série Biologia, v.14, n.1, p.07-24, 2002.

SÃo PAulo. Atlas Ambiental do Município de São Paulo - O verde, o território, o ser humano. São Paulo: SVMA, 2004. 266p.

SILVA FILHO, D. F.; BORTOLETO, S. Uso de indicadores de diversidade na definição de plano de manejo de arborização viária de Águas de São Pedro, SP. Revista Árvore, v. 29, n. 6, p.973-981, 2005.

SILVA, L. F. da Situação da arborização Viária de espécies para os bairros Antônio Zanaga I e II, da Cidade de Americana, SP. 2005. 80f. Dissertação (Mestrado em Agronomia, área de concentração Fitotecnia) Escola Superior de Agricultura “Luis de Queiroz”, Universidade de São Paulo, Piracicaba, 2005. 